\title{
NOTES SOBRE ELS SUBSIDIS DE L'ESGLÉSIA CATALANA PER A LA GUERRA DE SARDENYA \\ (1354)
}

PRIM BERTRAN I ROIGÉ

Universitat de Barcelona

A la Regina, pel do de la seva amistat

\section{SUMARI}

I. Generalitats.- II. Els subsidis de 1354: 1. L'exemple del bisbat de Girona. 2. El cas del bisbat d'Urgell. 3. El subsidi del bisbat d'Elna. 4. El subsidi del bisbat de Vic. 5. El subsidi del bisbat de Barcelona. 6. L'ajut del bisbat de Lleida. 7. El subsidi del bisbat de Tarragona. 8. El subsidi de l'abadia de Poblet.- III. Cloenda.

\section{GenERALITATS}

Hom coneix a grans trets la participació del clergat catalano-aragonès a les contribucions ordinàries a favor de la Corona. Sabem també del complex teixit de privilegis i peculiaritats que enmarcaven les relacions de l'Església i els sobirans en les qüestions fiscals, i que els furs i el dret canònic garantien. Els subjectes d'aquests status podien ésser religiosos

\footnotetext{
'Aquest treball s'ha realitzat en el marc del projecte PB95-0073 de la DGICYT. Agraeixo als Drs. Manuel Sánchez i Pere Ortí la informació donada sobre les fonts documentals de l'ACA.

"Anuario de Estudios Medievales". 29 (1999)
} 
concrets, bisbats sencers, jerarquies eclesiàstiques o els vassalls i homes propis de tots o de qualssevulla d'ells.

Avui per avui, tot i comptar amb múltiples estudis, monogràfics o no, queda encara molt per fer i molt per conèixer fins avaluar l'abast i la complexitat del procés de transferència de la renda eclesiàstica a la Corona, per qualssevol de les distintes puncions fiscals, i per saber també qui o quins eren els afectats, si els propis eclesiàstics o els seus vassalls, o tots alhora ${ }^{2}$.

Amb el temps, les contribucions dels eclesiàstics als pressupostos ordinaris de la Corona acabaren convertint-se en una autèntica anècdota, gràcies als privilegis i exempcions reiteratius u parcials o generals, que feren de l'Església i dels eclesiàstics un grup pràcticament immune a la fiscalitat ordinària de la Corona, és a dir, del conjunt d'entrades regulars de l'Estat que donaven estabilitat i marge pressupostari a les finances reials.

Els impostos extraordinaris foren sovint el motiu més important de discrepàncies, tant per part de l'Església en els seus concilis o en les directrius del papat, com també per les friccions entre monarquia i església. De les deliberacions eclesiàstiques en restà ferma la idea que el clergat del país havia de romandre exempt de qualsevol exacció arbitrària o extraordinària. I en tot cas, si per convicció o per pressions polítiques, el clergat d'un territori s'avenia a participar en una tributació extraordinària, calia l'autorització corresponent del papat.

La varietat de les contribucions extraordinàries de la clerecia és notòria, tant des del punt de vista tipològic com també dels resultats econòmićs de cada tipus impositiu. A manera d'introducció, i sempre amb un caràcter genèric, potser val la pena recordar les més notables i sovintejades.

1) Les demandes.

Es tracta de contribucions demanades en moments i circumstàncies molt determinades, establertes per les lleis generals del país, com podien ser la coronació del rei i/o la reina (coronatges) ${ }^{3}$, el matrimoni d'algun membre

\footnotetext{
${ }^{2}$ Vid. ampli plantejament a Manuel SÁNCHEz MARTínEZ, El naixement de la fiscalitat d'Estat a Catalunya (segles XII-XV), Eumo Editorial-Universitat de Girona, Vic, 1995, p. 125.

${ }^{3}$ Vid. l'interessant treball de Roser Salicrú I LluCh, Les demandes de la Coronació de Ferran d'Antequera $i$ d'Elionor d'Alburquerque al Principat de Catalunya. Una primera aproximació, a "Fiscalidad real y finanzas urbanas en la Cataluña Medieval", Barcelona. CSIC, Institución Milá y Fontanals, 1999, pp. 91-99.
} 
de la família reial (maridatges) o les necessitats urgents per motius de conflictes bèl-lics que requereixen ajudes de caire extraordinari.

2) Les profertes de les Corts.

Són les aportacions sol-licitades pel Rei a les Corts i acordades amb els braços $i$, en conseqüència, pagades pels estaments, ja sigui directament 0 , més tard, a través de la Diputació del General. Aquests tipus d'ajuts, que es consolidaren en els anys centrals del segle XIV, amb motiu de la preparació de les guerres mediterrànies; eren votats per les Corts i solien gravar quatre articles: vi, carn, cereals i draps ${ }^{4}$, amb el ben entès que els diferents estaments podien quedar-se fins un terç de les col-lectes en cada un dels territoris, fet que permetia que el control de l'impost s'escapés dels agents reials ${ }^{5}$, almenys en els terrtoris de barons i eclesiàstics.

3) Els subsidis eclesiàstics.

Com la resta de les contribucions especials o extraordinàries fetes a la Corona per part dels eclesiàstics, aquesta tipologia també té el caràcter de voluntària. A diferència del que hem vist fins ara, els subsidis eren contribucions realitzades després d'un repartiment, ja que es partia d'una sol-licitud o contribució global que després s'havia de distribuir entre els diferents individus tributaris. Evidentment, aquest tipus de tributació implicava que abans s'havia de fer o s'acceptava la taxa amb què cada benifet $\mathrm{o}$ càrrec estava gravat $\mathrm{o}$ era avaluat. De manera similar als precedents, com que es carregava sobre una persona o càrrec en funció dels seus dominis, vassalls, etc., els tributaris podien i solien carregar la contribució sobre els habitants de les seves jurisdiccions o els seus vassalls ${ }^{6}$. Tanmateix per acceptar-lo calia l'aprovació pontifícia o la d'un sínode que acordés de consentir-hi ${ }^{7}$.

${ }^{4}$ M. Sánchez Martínez; P. Ortí Gost (Edició a cura de), Corts, Parlaments i Fiscalitat a Catalunya: Els capítols del donatiu (1288-1384). Departament de Justícia-Generalitat de Catalunya, Barcelona, 1997, apèndixs XII i XIV.

${ }^{5}$ Manuel SÁnChez MARTínEZ, El naixement de la fiscalitat, p. 120.

${ }^{6}$ Només cal observar els pròlegs de les demandes de cada bisbat, on s'hi especifica clarament que el "subsidi" grava càrrecs i dignitats eclesiàstiques i els seus homes i, a vegades només els homes d'Església.

${ }^{7}$ Winfried KüCHLER, Les Finances de la Corona d'Aragó al segle XV (Regnats d'Alfons V i Jo(In II), Edicions Alfons el Magnànim, València, 1997. pp. 212-213. 


\section{4) La Dècima apostòlica.}

Sens dubte és una de les més importants aportacions fiscals de la clerecia a la Corona ${ }^{8}$. A diferència de totes les anteriors imposicions, aquesta es tracta d'un tribut eclesiàstic i sobre eclesiàstics, en funció dels ingressos anuals de cada clergue o de cada benifet, d'acord amb una taxació prèvia. Tanmateix la diferència rau encara en el fet que és el Papa - per tant no l'església del país, sinó un altre estat - qui decideix cedir-lo íntegra o parcialment -sovint dues terceres parts - a favor del Rei, que addueix les guerres contra l'Islam i el caràcter de croada d'aquests enfrontaments bèl-lics, o bé eren la manera de comprar la fidelitat a un dels papes -el d'Avinyó- enmig dels conflictes del Cisma d'Occident. En qualsevol cas, com diu M. Sánchez, «desde los últimos años del Doscientos hasta el final del Medioevo, las décimas percibidas de los eclesiásticos, en virtud de la plenitudo potestatis del Papa, fueron probablemente más provechosas para las finanzas de los reyes que para los pontífices»". Tanmateix, ni que bona part del tribut anés a parar a la Corona, en canvi, els eclesiàstics continuaren controlant al complet tot el procés d'exigència i percepció, mitjançant els col-lectors nomenats per Avinyó; d'aquesta manera, la Cambra Apostòlica s'assegurava possibles usurpacions o cobraments indeguts ${ }^{10}$.

En un principi, la «dècima» va ser la detracció del $10 \%$ sobre la totalitat de la renda eclesiàstica, fixada per les distintes taxacions i que acabà fossilitzant-se, sovint durant anys i àdhuc dècades. D'aquesta manera, en una etapa avançada del segle XIV ja no solia equivaldre a la desena part de les rendes, sinó a una quantitat sovint menor ${ }^{\prime \prime}$, que només solia revisar-se amb el canvi d'obtentor del benefici, i encara no sempre.

El desfasament entre la taxa i les rendes que havien de reflectir va fer que els clergues del primer terç del segle $\mathrm{XV}$, que havien vist reduïdes

\footnotetext{
${ }^{8}$ Vid., com a valoració global en el conjunt de la fiscalitat reial, Miguel Ángel LADERO QUESADA, El ejercicio del poder real: instituciones e instrumentos de gobierno, "Actas del XV" Congreso de Historia de la Corona de Aragón", Zaragoza, Diputación General de Aragón, 1994, I-1, pp. 115-121.

${ }^{9}$ Manuel SÁNCHEZ MarTínEZ. Fiscalidad pontificia y finanzas reales en Cataluña a mediados del siglo XIV: las décimas de 1349, 1351 y 1354, "Estudis Castellonencs", 6 (1994$95)$, p. 1280.

${ }^{10}$ Aquestes observacions les fa per a la Corona de Castella, tot diferentciant la "dècima" de les "tercias reales", Miguel Angel LADERO QUESADA, Fiscalidad y poder real en Castilla (1252-1369), Editorial Complutense, Madrid, 1993, p. 205.

"Miguel Ángel Ladero Quesada, Fiscalidad y poder real, p. 203.
} 
les seves rendes a causa de pestes, guerres i males collites, aconseguiren del papa Martí V (1423) la possibilitat de reduir de forma general les taxes a la meitat del seu valor i per a tota la Corona catalano-aragonesa ${ }^{12}$. I encara, més tard, el papa Eugeni IV (1443) d'acord amb el rei Alfons el Magnànim, ordenà una «manifestació de les rendes e valors de les prelatures, dignitats e beneficis» de la Confederació, per tal d'ajustar el càlcul fiscal a les dades dels valors reals de cada benifet. I la pressió exercida sobre els eclesiàstics tingué com a resultat la confecció d'una nova taxa ${ }^{13}$, que es va mantenir fins al 1457.

Cal fer constar que d'aquest tribut - la Dècima- n'estaven exempts els clergues amb rendes anuals inferiors als $20 \mathrm{~s}$. anuals, i alguns ordes religiosos, com el Císter, la Cartoixa, els mendicants i els membres dels Ordes Militars, en tant que els primers excel-lien per la seva pobresa i els segons ja acomplien - amb escreix - en la defensa de la Cristianitat. Precisament, l'imposició de la "Dècima" es justificava en ajuda dels Llocs Sants de Jerusalem i en la guerra contra l'Islam. Amb el temps, sobretot d'ençà de mitjans de segle XIV, la riquesa d'alguns d'aquests ordes -en principi considerats exempts per raó de l'observació estricta del vot de pobresa - féu que acabessin taxats i se'ls exigís tributar, no en tant que comunitat monàstica sinó per cada un dels càrrecs o dignitats que tenien adscrites rendes pròpies; l'exemple dels cistercencs, dels hospitalers o dels cartoixans pot ser significatiu en aquest sentit.

\section{ELS SUBSIDIS DE 1354}

Les revoltes dels Doria i dels seus aliats els Arborea de Sardenya, així com la generalització del conflicte i de la rebel-lia a l'illa sarda -havia deixat el territori de la Corona pràcticament reduit a pocs castells ${ }^{14}-$, varen condicionar i forçar el projecte d'intervenció militar de Pere el Cerimoniós, prevista, primer pel mes d'abril, i després ajornada per motius econòmics $\mathrm{i}$ personals, fins al mes de juny.

\footnotetext{
${ }^{12}$ Winfried KüCHLER, Les Finances de la Corona d'Aragó al segle XV, p. 230.

${ }^{13}$ Winfried KüCHLER, Les Finances de la Corona d'Aragó al segle XV, p. 232.

${ }^{14}$ Vid. Prim BERTRAN RoIGÉ, La nobleza catalana y la guerra de Cerdeña. La expedición de 1354, "Hidalguía", 271 (Madrid, 1998); pp. 737-754.
} 
Són conegudes amb força minuciositat les ajudes oficials (profertes) de municipis i estaments, pactades a través de les Corts i Parlaments catalans per l'afer de Sardenya ${ }^{15}$. Però la marxa dels esdeveniments militars, el cost i la complexitat dels preparatius bèl-lics, menaren el Rei a demanar a l'Església i als seus vassalls un ajut extraordinari ${ }^{16}$, que havia de ser fixat i pactat al parlament de Vilafranca del Penedès, el 10 de gener, en una reunió conjunta de bisbes, abats i comanadors de l'Orde de l'Hospital ${ }^{17}$. Amb anterioritat (11 de novembre de 1353) havia demanat un ajut de 100.000 s.j. al Castellà d'Amposta, Juan Fernández de Heredia, pels seus homes de la Castellania ${ }^{18}$, tant els del regnes d'Aragó i València com els del Principat de Catalunya ${ }^{19}$; l'Orde de Montesa s'havia avingut a oferir 50.000 s.b., i la de Santiago 15.000 s.j. Les línies i els documents que seguiran volen ser una primera aportació al tema, que recerques posteriors i de més ample abast haurien de completar i - si cal- matisar.

No he pogut localitzar l'efectivitat i compliment d'aquests subsidis en cada un dels clergues a qui es féu la petició. En canvi sí que coneixem la proposta reial i la sol-licitud feta a algunes de les dignitats eclesiàstiques i als seus vassalls, sense "preiudici a les libertats e privillegis ecclesiàstiques $»^{20}$. En tant que percepcions extraordinàries, havien de ser autoritzades pels papes o pels concilis provincials, i fins i tot pot donar-se el cas que alguns clergues puguin negar-se a contribuir tot i l'aprovació pontifícia, al-legant dificultats econòmiques o de qualsevol altra mena; en aquests casos,

\footnotetext{
${ }^{15}$ Manuel SÁNChez Martínez, Corts, Parlaments i Fiscalidad en Cataluña: Las "profertes" para las guerras mediterráneas (1350-1356), "Actas XV Congreso Historia de la Corona de Aragón” (Diputación General de Aragón, Zaragoza 1994), I-4. pp. 251-272.

${ }^{16}$ Manuel SÁNCHEZ MARTínEZ, Fiscalidad pontificia y finanzas reales en Cataluña a mediados del s. XIV., p. 1290.

${ }^{17} \mathrm{ACA}$, Cancelleria [en endavant C], reg. 1398, fols. 24 r. i $30 \mathrm{r}$.

${ }^{18} \mathrm{ACA}, \mathrm{C}$, reg. 1398, fols. 1v.-2r.

${ }^{19} \mathrm{No}$ conec la resposta de l'Orde de l'Hospital, tanmateix, en aquest any 1353, la sol.licitud d'un ajut extraordinari per a subvenir la guerra contra Gènova, i la promesa del Gran Prior de Catalunya d'aportar 20.000 s.b., aixecà les protestes de jurats, prohoms i habitants de viles i llocs del Priorat de Catalunya, reunits a l'església de Taradell, ja que se'ls taxà sense consultarlos. Entre les comandes i viles taxades en aquella ocasió, hi consten: L'Espluga Superior, 98 £.b.; l'Espluga Inferior, £.b.; Granyena, 80 £.b.; Barberà, 38 £.b.; Vallfogona de Riucorb, 920 s.b.; Pira, 10 £.b. (ACA: SJJ, sec. $1^{\mathrm{a}}$, arm. 18, perg. 1).

${ }^{20} \mathrm{ACA}, \mathrm{C}$, reg. 1398, f. 52v.-53r.: «Item que 1 senyor Rey los farà carta per aquest do que ara li faran no sia fet preiudici a les libertats e privillegis ecclesiàstiques ne a lurs hòmens e que no Is sia tret a conseqüència, ans romanguen en aquella libertat e franquesa que eren e són ans d'aquest do que faran".
} 
per alliberar-se de les exigències reials o de les dels funcionaris reials, els clergues solien acudir a Avinyó per cercar el recolzament del papa. Potser el cas més clar és el del capítol catedralici d'Urgell (21 de gener de 1354) que aconsegueix el suport d'Innocenci VI davant les exigències il-legals $i$ àdhuc violentes dels oficials reials ${ }^{21}$.

Les propostes de quantitats a recollir en cada diòcesi representaven muntants globals diversos en funció de les taxacions i prenien com a referència els subsidis oferts pels eclesiàstics amb motiu de l'anterior expedició dels temps de Jaume II i duta a terme per l'infant Alfons, el futur rei Benigne ${ }^{22}$. Amb tot, es tracta de quantitats orientatives, de manera que els procuradors reials tenien la capacitat de reduir-les o d'adequar-les a les situacions econòmiques adients i reals, si això era just i necessari. La major part d'aquests subsidis pactats als parlaments de Vilafranca-Barcelona a principis de gener, estan relacionats en els apartats corresponents a cada bisbat.

Per fer efectiu el subsidi, els bisbes deurien reunir la resta de prelats i altes dignitats eclesiàstiques taxades dins de cada bisbat, per posar-se d'acord i fer el repartiment, pagament i taxació dels súbdits amb els mateixos criteris i de manera més o menys coordinada. Coneixem el cas del bisbat de Girona, on «lo dit bisbe per la dita rahó ha convocats e manats venir a Gerona los dits prelats e persones eclesiàstiques de son bisbat ${ }^{23}$.

Tan sols en alguns casos podem observar que no deuria ser tan ràpid el cobrament com el monarca hauria desitjat - ho volia per al proper mes de març del mateix any 1354-, així, per exemple, es refereix al bisbe de Girona i a l'abat de Banyoles (18 de febrer de 1354) i els acusa d'endarrerir el pagament del subsidi: «prenen algunes maneres per alargar e minvar les quantitats ordonades per lo subsidi a ells demanador $»^{24}$, i els recorda que

\footnotetext{
${ }^{21}$ Johannes VINCKE, Documenta Selecta. Mutuas civitatis Arago-Cathalaunicae et Ecclesiae relationes illustrantia, Biblioteca Balmes, Barcelona, 1936, doc. 545, p. 411.

${ }^{22} \mathrm{ACA}, \mathrm{C}$, reg. 1398, fol. 52v.-53r.: «Item deya a emprar pregant lo bisbe e el capítol e la sgleya de Girona que dels hòmens lurs li faien tal do e ajuda que al dit senyor sia profitosa e prenedora com en lo viatge que el rey n'Amfòs féu en Cerdenya la sgleya de Girona li féu ajuda de L mill sòlidos, los quals pagaren los hòmens lurs. $\mathrm{E}$ ara que ha haut de la sgleya de Barchinona e $\bullet$ de son capítol, qui és molt pobre e qui no ha quaix gens d'òmens, en ajuda d'aquest viatge M lliures". Vid. també Angel FàBrEGA Grau, Ayuda económica de la Iglesia a Jaime II para la conquista de Cerdeña, "Anthologica Annua", XI (1963), pp. 41-44.

${ }^{23} \mathrm{ACA}, \mathrm{C}$, reg. 1398 , fols. $69 \mathrm{r}$.-v.

${ }^{24} \mathrm{ACA}, \mathrm{C}$, reg. 1398, fol. 86r.
} 
han de pagar la taxa acordada, «car si axí no ho fahien donarian a nostre viatge grant torb e a nos grant dapnatge e deshonor, perquè us manam que vos $a b$ gran diligència façats vostre poder en haver d'ells ço que ordenat és ${ }^{25}$. A principis de maig, el col·lector i porter reial encarregat de cobrar els subsidis del bisbat de Vic, havia aconseguit finalment rebre els 5.600 s.b. que restaven pagar al bisbe i capítol osonencs ${ }^{26}$. L'infant Pere, a mitjans de juliol del mateix any, urgia el Castellà d'Amposta, de l'Orde de l'Hospital, per a que fes pagar els diners de l'ajuda promesa ${ }^{27}$ per tal que aquest cobrament fos efectiu el més aviat possible i servís per eixugar les enormes despeses de l'expedició. Tanmateix, la Castellania d'Amposta s'oferí (25 de novembre del 1354) a ampliar l'ajut econòmic a altres 35.000 s.j., quantitat que es cobraria de tots els vassalls, tant cristians com musulmans o jueus, excepte els Cavalleria i els Eleazar de Saragossa ${ }^{28}$.

Tot fa pensar que a principis d'agost de l'any següent (1355) s'haurien fet ja els comptes totals del que aportaren els eclesiàstics i els seus vassalls $\mathrm{i}$ les ciutats reials. La suma global per ambdues procedències pujà a 196.375 £.b i 31.942 florins d'or (19.165 £. 4 s.b.) o sigui, un total de 215.540 f. 4 s.b..$^{29}$. Malauradament no he pogut esbrinar quina va ser l'aportació exclusiva de la clerecia i/o dels homes de jurisdicció eclesiàstica.

En quant al repartiment de la col-lecta entre els vassalls eclesiàstics, s'observa que la taxació prèvia la realitzava el senyor jurisdiccional o els seus batlles, d'acord amb els jurats i prohoms dels respectius municipis ${ }^{30}$. I acte seguit podien ser els mateixos batlles -aquest és el cas dels vassalls de l'abadia de Ripoll ${ }^{31}$ - qui s'encarreguessin de la col-lecta, o bé confiarla als representants del municipi, els quals farien recollida i lliurament de les quantitats globals que corresponien a cadascun dels comuns - com passa amb

\footnotetext{
${ }^{25}$ Ibid.

${ }^{26}$ Ibid., fol. $102 \mathrm{r}$.

${ }^{27} \mathrm{ACA}, \mathrm{C}$, reg. 1606 , fol. $11 \mathrm{r}$.

${ }^{28} \mathrm{ACA}, \mathrm{C}$, reg. 1606 , fols. $139 \mathrm{r} .-140 \mathrm{r}$.

${ }^{29} \mathrm{ACA}, \mathrm{MR}$, reg. 642 (Albalaes), fols. 101v.-105v.

${ }^{30}$ «...Abbats, priors o persones ecclesiàstiques fan ajuda al dit senyor Rey per la dita rahó e taxar lurs hòmens de pagar les dites quantitats segons que a cadascú de lurs senyors serà vist..." (ACA, C, reg. 1398, fol. 53r.).

${ }^{31} \mathrm{ACA}, \mathrm{C}$, reg. 1398, fol. 101v.
} 
als vassalls del monestir de Poblet ${ }^{32}-$. Fins i tot hi havia la possibilitat d'enviar un col-lector especial per acabar de recollir els diners impagats per part de vassalls o per algunes dignitats eclesiàstiques - així succeeix amb un terç del total que encara havien de fer efectiu el bisbe i el capítol de $\mathrm{Vic}^{33}-$

Tanmateix en altres territoris d'eclesiàstics, després de les taxacions dels senyors, eren els procuradors reials qui s'encarregaven de collir els subsidis. A manera d'exemple, podem adduir el cas del procurador Simó de Forest, encarregat de la col-lecta al bisbat de Vic, i a qui el monarca recorda ${ }^{34}$ que s'ha d'ajustar estrictament a exigir els diners a cada home dels monestirs de Ripoll i de Montserrat tal i com els han taxat els seus senyors - l'abat i prior, respectivament, d'aquells cenobis-.

Però també podia succeir que els vassalls d'eclesiàstics situats dins de territoris aliens a la casa de Barcelona, intentessin escapolir-se de la taxació i del pagament posterior per aquest fet, o que els senyors eclesiàstics no s'atrevissin a taxar-los pel mateix motiu. "En aquest cas, present als dits nobles o cadascú d'ells las letras que ls portarà de part del senyor Rey. E prech-los de part d'ell que no-ls desplàcia si los dits abbats, priors o persones ecclesiàstiques fan ajuda al dit senyor Rey per la dita rahó e taxar lurs hòmens de pagar les dites quantitats segons que a cadascú de lurs senyors serà vist e que los dits richs hòmens o lurs officials deguen aquells destrényer, axí com los officials dels senyor Rey faran aquells qui són poblats en la terra sua». I encara "que als abbats e priors qui són poblats en les terres dels richs hòmens segons que desús és oït de les persones ecclesiàtiques qui hauran lurs hòmens sia servada la forma e la manera que.ls fo servada en lo do que faeren al senyor Rey n'Amfòs con anà a Cerdenya per que no pusquen dir-los dits richs hòmens que nenguna novelletat ne prejudici los sia feyt $»^{35}$.

\footnotetext{
${ }^{32} \mathrm{ACA}, \mathrm{MR}$, reg. 336, fol. 9r. Vid. també Agustí Altisent, Història de Poblet, Abadia de Poblet, Poblet, 1974, pp. 232-234.

${ }^{33} \mathrm{ACA}, \mathrm{C}$, reg. 1398, fol. $102 \mathrm{r}$.

${ }^{34}$ Ibid., fol. $101 \mathrm{v}$.

${ }^{35} \mathrm{ACA}, \mathrm{C}$, reg. 1398 , f. 53 r.
} 


\section{L'exemple del bisbat de Girona}

La relació de les taxacions posa de manifest la diferent distribució i el pes distint de cada càrrec eclesiàstic (i dels seus vassalls) en el repartiment del subsidi.

Bisbe i capítol de Girona

$1.000 £$.

Abat de Sant Esteve de Banyoles

$300 £$.

Abat de Sant Pere de Galligants

$50 £$.

Abat de Santa Maria d'Amer

$100 £$.

Abat de Sant Feliu de Guíxols

$100 £$.

Abat de Besalú

$100 £$.

Abat de Sant Llorenç del Munt

$50 £$.

Abat de Camprodon

$50 £$.

Abat de Sant Pere de Rodes

$500 £$.

Abat de Santa Maria de Roses

$100 £$.

Abat de Sant Quirze de Colera

$50 £$.

Abat de Sant Miquel de Fluvià

$50 £$.

Abat de Santa Maria de Vilabertran

$150 £$.

Abat de Sant Salvador de Breda

$100 £$.

Prior de Santa Maria de Lledó

$100 £$.

Prior de Santa Maria en Frescastell de Besalú $\quad 100 £$.

Prior de Sant Quirze de Colera $\quad 25 £$.

Prior de Santa Maria de Ridaura $\quad 50 £$.

Prior de Sant Joan les Fonts $\quad 25 £$.

Paborde de Sant Martí de Girona $\quad 25 £$.

Prior de Sant Miquel de Cruïlles $\quad 50 £$.

Prior de Santa Maria de Cervià $\quad 25 £$.

Prior de Sant Pol de Mar $\quad 50 £$.

Prior de Santa Maria de Roca-rossa $\quad 50 £$.

Prior de Sant Pere de Cercada $\quad 50 £$.

Prior de Sant Martí de Junyà $\quad 50 £$.

Prior de Santa Maria de les Olives $\quad 15 £$.

Prior de Sant Tomàs $15 £$.

Monestir de Sant Feliu de Cadins $\quad 25 £$.

Monestir de Bell-lloc $\quad 15 £$.

Monestir de Sant Daniel de Girona $\quad 15 f$.

D'entrada hom pot adonar-se de l'adequació de cada tributari a tipus molt genèrics, múltiples o submúltiples de centenes, que situa el subsidi econòmic del bisbe i del capítol gironins en la banda més alta $(29,5 \%$ del subsidi), mentre queda a la meitat l'aportació de l'abat de Sant Pere de Rodes $(14,7 \%$ del subsidi), 'i ençara en un lloc rellevant l'abat de Sant 
Esteve de Banyoles (8,8\% del subsidi), seguit del de Vilabertran $(4,4 \%$ del subsidi), mentre que la resta es reparteixen quantitats -i percentatgesiguals o inferiors a les $100 £$. (equivalents al 2,9\% del total dels subsidis).

Almenys en el cas del bisbat de Girona ${ }^{36}$-ignoro si això també podia succeir en altres diòcesis- hi hagué una modificació de les quantitats estipulades per a alguns dels càrrecs i dignitats ${ }^{37}$. El 28 de gener del mateix any 1354, en plena preparació de l'expedició militar, el Rei autoritza al comissionat, Pere Sacosta, per a «que pusca fer aquells auments sobre lo dit subsidi que...li paregués faedor ${ }^{38}$. I tot fa pensar que deurien ser aquestes modificacions o ampliacions de darreries de mes les que es feren efecti$v^{2}{ }^{39}$. Les diferències proposades en la nova «empara» o demanda suposaven increments molt notables, com passar de 1.000 a $1.500 \mathscr{L}$. per part del

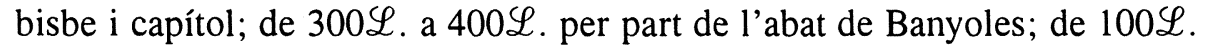

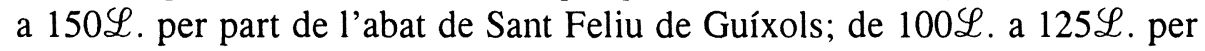

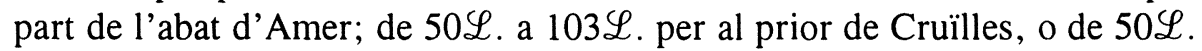
a $115 \mathscr{L}$. pel que fa a l'abat de Sant Pere de Camprodon. Només en un cas hi ha una substanciosa rebaixa: l'abat de Vilabertran, taxat primer en $150 \mathscr{L}$, i després rebaixat a tan sols 100 . I encara s'hauria d'afegir el priorat d'Ullà, taxat ara amb $75 \mathscr{L}$., quan en la primera relació no apareixia. Tanmateix aquestes revisions o «empares» afecten només alguns càrrecs $\mathrm{i}$ els seus vassalls, i per tant no sembla que tingués caràcter generalitzat, de la mateixa manera que tampoc tingué caràcter generalitzat l'ajut que estudiem. És evident que no tots els bisbats ni tots els càrrecs eclesiàstics hi van col-laborar o se'ls va demanar ajut, com succeí en el precedent viatge del temps d'Alfons el Benigne, i en el cas de Barcelona concretament, considerat un bisbat pobre i mancat d'homes als quals gravar ${ }^{40}$.

\footnotetext{
${ }^{36}$ Només s'ha conservat els comptes d'aquesta diòcesi, a l'ACA, MR, reg. 2461, quad. 5.

${ }^{37} \mathrm{La}$ nova relació o adequació és a l'ACA, C, reg. 1398, fols. 70 r.-v.

${ }^{38}$ Ibid., fol. $1 \mathrm{v}$.

${ }^{39} \mathrm{ACA}, \mathrm{MR}$., reg. 2461 , quad. 5. El problema que ofereixen les anotacions d'aquesta capta rau en què no sempre s'especifica el senyor eclesiàstic al qual pertanyen els homes.

${ }^{40}$ «Item deya a emprar pregant lo bisbe e el capítol e la sgleya de Girona que dels hòmens lurs li faien tal do e ajuda que al dit senyor sia profitosa e prenedora com en lo viatge que el rey n'Amfòs féu en Cerdenya la sgleya de Girona li féu ajuda de L mill sòlidos, los quals pagaren los hòmens lurs. E ara que ha haut de la sgleya de Barchinona e de son capitol, qui és molt pobre e qui no ha quaix gens d'òmens, en ajuda d'aquest viatge, M lliures» (ACA, C. reg. 1398, fols. 52 v. -53 r.).
} 


\section{El cas del bisbat d'Urgell}

La col-lecta del subsidi al bisbat d'Urgell es confia a Pere de Montcada, amb ordres molt estrictes per a la percepció de les quantitats: «Item, que deman als dits bisbe o vicaris seus e als altres prelats e clergues d'Urgell, per la dita rahó, les quantitats deval scrites com hagut esguart a açò que.ls altres prelats han donat per què sia cosa rahonable e justa».

«E si el dit procurador trobava sobre açò resistència e los damunt dits recusaven fer al senyor Rey la dita ajuda, lavors, ab les host de Catalunya o d'aquests lochs que li serà viares, faça execució [..]vilment $\mathrm{e}$ poderosa en los lochs del dit bisbe, capítol e prelats, clergues e pesones eclesiàtiques com los hòmens entrò a les quantitats dejús scrites, com açò sia degut a fer al senyor Rey e així ho ha haut de consell [..] pot fer en aquest cas. E açò.s faça en tal manera que.l senyor Rey ho pusque haver de present o almenys per tot lo mes de maig primer vinent les dites quantitats. Però si la dita resistència [li] era feta ans que faés la execució peria que la degués fer e començar en los lochs que.ls damunt dits han dins la jurisdicció del senyor Rey, per previment de persones e de béns ${ }^{41}$.

Els ajuts pecuniaris per raó de subsisdi que haurien hagut d'aportar els clergues i els homes d'església del bisbat d'Urgell són, en xifres absolutes, les més destacades (un total de $5.780 \mathfrak{f}$ ) de les que figuren a la relació següent:

Del bisbe d'Urgell o de les seves iendes

$500 £ . b$

Del capitol d'Urgell o de les seves rendes

500 f.b.

Dels homes del bisbe d'Urgell

$3.000 £ . b$

Dels homes del paborde de Solsona

$400 £ . b$

Del lloc de Tremp

600 £.b.

Dels homes de l'abat de Cardona

$150 £ . b$

Dels homes del prior d'Organyà

80 f.b.

Dels homes del prior de Castellfolit de Riubregós

Dels homes de l'abat d'Àger

[en blanc]

Dels homes de l'abat de Bellpuig de les Avellanes

$150 £ . b$

Dels homes de l'abat de Gerri

$150 £ . b$

150 £.b.

Dels homes de l'abat de Lavaix

$50 £ . b$.

Dels homes del prior de Sent Serni de Tavèrnoles

50 £.b.

Totes les dites quantitats pugen a 7.280 $£$.

\footnotetext{
${ }^{41}$ ACA, C, reg. 1400, fols. 154r.-155v.
} 
Hom hi pot apreciar la importància de les taxes sobre els homes dels monestirs, però sobretot la dels homes del bisbe, tots els quals paguen el $51,9 \%$ del conjunt total. A part hi ha el $8,6 \%$ del mateix bisbe -a títol personal-i el mateix percentatge atribuït al capítol catedralici. L'enviament de Pere de Montcada com a procurador encarregat d'obligar i exigir a bisbe, prelats i clergues les quantitats relacionades, en una data tan tardana, com és a mitjans d'abril del 1354, i la referència explícita a les resistències ofertes o a possibles recusacions «Totes les dites quantitats ${ }^{42}$ que pugen a $7.280 £$., vol lo senyor Rey que sien haudes dels prelats e hòmens damunt dits. Emperò vol lo senyor Rey que, si per ventura lo dit procurador trobava que alcuns fossen massa taxats e alcuns poch, que ell tolgués als uns e assignés als altres, segons que li serà viares. E si totes les dites quantitats no podia haver segons la dita taxació, scriu-ne al Consell del senyor Rey que és a Barcelona, clarament sa enten[...]».

\section{El subsidi del bisbat d'Elna}

Com altres, deuria ser sol-licitat a principis de gener, amb la intenció que fos recollida la quantitat en un termini que no ultrapassés el mes de març. Els senyors eclesiàstics - com succeïa en altres indrets- s'encarregaven de taxar els seus súbdits i/o les comunitats vilatanes.

S'hi pot apreciar la destacada importància, en primer lloc del bisbe i capítol d'Elna, i en segon terme, de l'abadia de Cuixà ${ }^{43}$.

Bisbe d'Elna i el seu capítol i llurs homes

\footnotetext{
${ }^{42} \mathrm{La}$ quantitat total que dóna aquest capítol no coincideix amb la suma de les quantitats fixades a cada un dels capítols, els quals pugen a 5.780£.b., a les quals caldria afegir-hi la quantitat desconeguda atribuible al priorat benedictí de Castellfollit de Riubregós, que difícilment podem creure que aportaria les $1.500 £$.b. que manquen.

${ }^{43}$ Sobre la importància de les rendes d'aquesta abadia benedictina, en comparació amb les de la mensa episcopal, per a la darrera dècada del segle XIV, vid. Prim BERTRAN, La dècima apostòlica: L'exemple d'Elna (1391), "Estudios sobre renta, fiscalidad y finanzas en la Cataluña bajomedieval", dir. per M. SÁNCHEZ MARTínEZ, CSIC-Inst. Milà i Fontanals, Barcelona, 1993, p. 462 .
} 
Abat de Sant Martí del Canigó amb els seus homes

\section{El subsidi del bisbat de Vic}

Com s'ha dit anteriorment, els prelats del bisbat de Vic haurien pactat $\mathrm{i}$ ofertat les quantitats del subsidi en la reunió de Vilafranca del 10 de gener del $1354^{44}$. Una part s'haurien pagat amb certa rapidesa, just el $64,1 \%$ del promès, abans de primers de març ${ }^{45}$. En canvi, en les mateixes dades, no havien satisfet les seves quantitats cap dels monestirs i canòniques relacionats ${ }^{46}$ a continuació, cada un dels quals consta amb la seva respectiva taxació.

Abat de Santa Maria de Serrateix $\quad 50 £ . b$

Abat de Santa Maria de l'Estany $\quad 150$ £.b

Prior de Sant Miquel del Fai $\quad 60$ £.b

Abat de Sant Llorenç del Munt $\quad 25 £$.b

Paborde de Santa Maria de Manresa $\quad 100$ £.b

\section{El subsidi del bisbat de Barcelona}

No coneixem si es va dur a terme alguna col-lecta entre els vassalls dels eclesiàstics del bisbat de Barcelona. Els prelats foren convocats per ajudar l'empresa de Sardenya, amb tot no he trobat constància que es fes

\footnotetext{
${ }^{44}$ ACA, C, reg. 1398, fol. 24r.

${ }^{45} \mathrm{ACA}, \mathrm{C}$, reg. 1398, fol. 102r. Quedaven per pagar 5.600s.b., dels 15.600 promesos.

${ }^{46} \mathrm{ACA}, \mathrm{C}$, reg. 1400 , fols. $79 \mathrm{r}-\mathrm{v}$.
} 
efectiu la col-lecta i l'ajut. Tanmateix sabem que hi hagué la promesa de col-laborar-hi amb mil lliures: «E ara que ha haut de la sgleya de Barchinona e de son capítol, qui és molt pobre e qui no ha quaix gens d'òmens, en ajuda d'aquest viatge $M$ lliures ${ }^{47}$. Es tracta, però, d'una promesa que no he pogut corroborar.

\section{L'ajut del bisbat de Lleida}

Al bisbat de Lleida l'única aportació substancial i destacada al subsidi la feren el bisbe, el capítol i els seus vassalls, que equival al $80 \%$ de la petició, tal com apreciar-se a la relació següent. Monestirs i canòniques, tot i la rellevant importància de Sigena o de Roda, se'ls demanen aportacions gairebé testimonials ${ }^{48}$.

Bisbe i capítol, amb els seus vassalls

Monestir de Sant Hil-lari amb els seus vassalls $\quad 25$ £.b

Prior de Roda d'Isàbena, amb els seus homes $\quad 100 £ . b$

L'abat d'Escarp amb els seus homes $\quad 100 £$.b

\section{El subsidi del bisbat de Tarragona}

Al bisbat de Tarragona les aportacions pel subsidi es limiten a dos monestirs i quatre rectories «e alclines altres persones eclesiàstiques qui són dins lo archabisbat de Tarragona que.ns donen genrosament les quantitats en una cèdula en les presents enclosa se contenen [...] Enformant-nos que nostre enteniment és que ço que us deïm pusquem haver de lurs hòmens $\mathrm{e}$ que lurs senyors los taxen. E si los hòmens volenterosament no.s ho volen donar de us qui be en altra manera no.s farien fer la execució contra los hòmens pus a lurs senyors plagués...» ${ }^{49}$ :

\footnotetext{
${ }^{47} \mathrm{ACA}, \mathrm{C}$, reg. 1398 , f. 52 v.

${ }^{48} \mathrm{ACA}, \mathrm{C}$, reg. 1398 , fol. 30v.-31r.

${ }^{49} \mathrm{ACA}, \mathrm{C}$, reg. 1398 , fols. 30v. $-31 \mathrm{v}$.
} 
$\begin{array}{lr}\text { Cartoixa de Scala Dei } & 100 £ . b \\ \text { Monestir de Bonrepòs } & 50 \\ \text { El rector de Montblanc } & 50 £ . b \\ \text { El rector de Valls } & 100 £ . b \\ \text { El rector de Reus } & 50 £ . b \\ \text { El rector de Tivissa } & 100 £ . b \\ \end{array}$

En la relació no hi consten les grans abadies cistercenques de Poblet i Santes Creus. Ambdues foren cridades a part, i els seus vassalls taxats d'acord amb els criteris seguits en subsidis precedents. En veurem el cas de l'abadia de Poblet.

\section{El subsidi de l'abadia de Poblet}

El monestir de Poblet, atesa la seva singular importància, no consta relacionat — com s'ha dit- entre els de l'arquebisbat de Tarragona. Fou especialment i particularment requerit pel monarca a subvenir les despeses de l'expedició a Sardenya, el 20 de febrer del 1354, i pagà el «subsidi» d'acord amb el volum dels seus vassalls, repartits en diferents diòcesis i vegueries. Les $1.500 £$. o 25.000 sous fixats, varen ser recollits entre les poblacions del seus dominis, d'acord amb les respectives capacitats econòmiques $\mathrm{i}$ demogràfiques ${ }^{51}$. S'hi pot apreciar com la major part de la càrrega $(16,2 \%)$ recaigué sobre els habitants de Verdú, seguits dels de Vinaixa (9\%) i els del Vilosell (9\%), i, més distants, els de Vimbodí $(7,6 \%)$. Les poblacions de la baronia d'Urgell hi col-laboraren amb quantitats minses en comparació amb les anteriorment referides; s'hi poden destacar les aportacions de Castellserà $(3,3 \%)$ i Bellcaire $(1,9 \%)$. Entre totes les poblacions del senyoriu pobletà s'hi recolliren 25.000 sous, als que s'hi varen afegir altres $5.000 \mathrm{~s}$. per composició feta amb el Tresorer reial, per arrodonir el montant total, tot i que s'especifica qui i sota quines condicions el va sufragar. D'aquesta manera, la quantitat global lliurada pels vassalls de

\footnotetext{
${ }^{50}$ El 18 d'abril del mateix any 1354 , quedà exempt de col.laborar en el subsidi a causa de la situació de misèria en què havia caigut després dels anys de la crisi derivada de la Pesta Negra (ACA, C, reg. 1400, fols. 167v.-168r.).

${ }^{51}$ Archivo Histórico Nacional, Madrid [AHN]. Clero (Poblet), papeles, legajo 6763, fols. 4r.-v. Referència àmplia a Agustí Altisent, Història de Poblet, Abadia de Poblet, Poblet, 1974 , p. 234.
} 
l'abadia pujava als $30.000 \mathrm{~s}$. tal com recull l'anotació del Tresorer ${ }^{52}$, de l'1 de març del 1354.

De Prenafeta, Miramar i Figuerola

Senan

Montblanquet

Fulleda

Els Omellons

Vinaixa

Tarrès

Vimbodí

El Vilosell

Vallbona o Pobla de Cèrvoles i La Fumada

Juncosa

Vall de Reig

Soleràs

Els Torms

La Cisquella

Albagès

El Cogul

Les Besses

La Manresana

Castellserà

Bellcaire

Butsènit

Bellmunt

Boldú

Montsuar

La Fuliola

Tornabous

Granyanella

Verdú

El Cudós

Els homes de Quart, vassalls de Poblet

Donaren, a més, per la composició del Tresorer reial

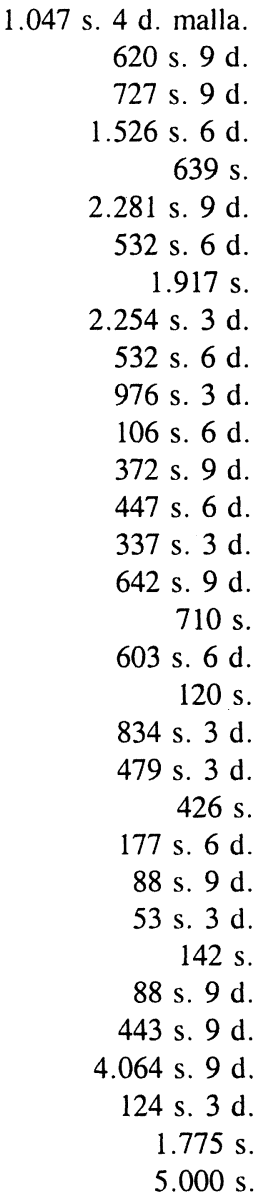

\section{CloENDA}

Les diferents taxacions amb què es gravaren els càrrecs i dignitats eclesiàstics - i, en conseqüència, els seus homes- no afecta tots els bisbats

${ }^{52}$ ACA, MR., reg. 336, 9 r. 
ni tots els prelats. Així, no he pogut constatar taxacions i cobraments dels bisbats de Barcelona ${ }^{53}$ i Tortosa, i potser aquests dos territoris s'hagin d'incloure entre els dels prelats i universitats que es negaren a col-laborar econòmicament en l'empresa ${ }^{54}$. Tanmateix a l'hora de quantificar les aportacions de cadascú ens hem de refiar dels llistats teòrics de les taxacions prèvies, ja que rarament els comptes de Tresoreria o els registres d'Albarans especifiquen amb detall els ingressos, per conèixer si, efectivament, cadascú aportà el seu, quant hi aportà i en quins terminis. També cal afegirhi el problema de la concentració d'algunes taxes per part de diverses institucions eclesiàstiques - segurament en funció de tenir un mateix senyoriu territorial i jurisdiccional- com és el cas ben concret de la taxació conjunta de bisbe i capítol corresponent, que fa impossible esbrinar quina part correspon a cadascú d'ells. En qualsevol cas, aquestes taxes són les més elevades a tots els bisbats, molt per sobre de la resta de prelats, i entre tots ells destaca el bisbe i capítol d'Urgell, amb els seus homes propis ${ }^{55}$.

He obviat fer qualsevol intent de comparació entre bisbats o institucions eclesiàstiques taxades per arriscat $\mathrm{i}$ inexacte, en tant que les relacions que figuren a cada bisbat o no els recullen tots perquè no tributen o no hem pogut localitzar - ara com ara - la resta dels que manquen, amb la seva corresponent taxació.

La col·lecta sobre vassalls d'eclesiàstics i els reials, a terres gironines $^{56}$, i les quantitats globals recollides en aquest mateix àmbit territorial, permeten veure que aquesta punció fiscal de caràcter extraordinari recaigué bàsicament sobre els homes dels territoris eclesiàstics, però també

\footnotetext{
${ }^{53}$ En canvi, sí que col.laboraren i pagaren l'ajut extraordinari per la guerra contra Castella, el 1357-58 (ACA, MR, reg. 339, fols. 12v.-13r. i reg. 340, fol. 20r.).

${ }^{54}$ Així s'afirma el 12 de febrer de 1357 (ACA, MR, reg. 642 (Albalaes), fols. 305r.-306r. Amb anterioritat (4 de febrer de 1356) el Mestre Racional, Berenguer de Codinachs, recordava que altres prelats i viles del bisbat de Girona, encara no havien fet efectiu el pagament de les aportacions compromeses, i els reclama amb urgència els diners (ACA, MR, reg. 642, fol. 171 r.).

55" Primerament pregan e ab bona manera haia del bisbe d'Urgell o de ses rendes: 500£.b. Item pregan del dit capítol o de lurs rendes: $500 £ \mathrm{fb}$

Item dels homes del bisbe d'Urgell, per força o per grat: 3.000£.b."

(ACA, C, reg. 1400, fols. 154v.-155v.).

${ }^{56} \mathrm{ACA}, \mathrm{MR}$, reg. 2461. A manera d'exemple, es pot observar el cas de la batllia de Camprdon, on la distribució dels diners aportats pels masos i bordes dels homes de la batllia queda així: Homes d'església: $57,7 \%$

Homes aloers: $10,1 \%$

Homes francs o «de si mateix»: $32,2 \%$
} 
sobre els mateixos eclesiàstics -insistim de nou, no sobre tots ni sobre tots els bisbats- que, en el cas dels pertanyents al bisbe d'Urgell, aquest paga -0 , si voleu, hi és taxat - amb un valor equivalent a la 1/6 part del conjunt dels seus vassalls.

\section{RÉSUMÉ}

L'apport économique du clergé catalan et de ses vassaux, dans le cadre du subside extraordinaire que le roi Pere IV le Cérémonieux leur réclama afin de mener à terme la guerre contre l'île de Sardaigne, au printemps 1354. On y trouve détaillées chacune des institutions impliquées, leur charge ecclésiastique ainsi que les sommes sollicitées.

\section{SUMMARY}

The economic participation of the Catalan ecclesiastic hierarchy and its subjects in the extraordinary tax which King Pere IV the Ceremonious demanded, in order to finance the war against the island of Sardinia during the spring of 1354. Each institution and ecclesiastical hierarchy is documented with the amount of money. 